\title{
Sistema para análise das outorgas de captação de água e diluição de efluentes na bacia do rio Piracicaba (MG)
}

\author{
System for analysis of water abstraction and effluent \\ dilution in Piracicaba river basin, Minas Gerais State, Brazil \\ Luana Lisboa** ${ }^{\mathbb{C}}$, Demetrius David da Silva² ${ }^{\mathbb{D}}$,

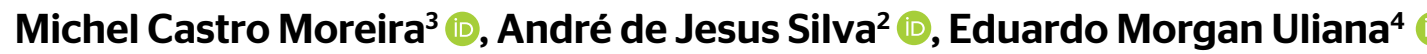

\section{RESUMO}

A outorga de direito de uso da água é um dos principais instrumentos de gestão para controle quantitativo e qualitativo dos recursos hídricos. Para sua implantação, é necessário, entre outras ações, definir critérios e desenvolver ferramentas para análise integrada dos aspectos quantitativos e qualitativos da água. Dessa forma, o objetivo do estudo foi desenvolver um sistema para análise das outorgas de captação de água e diluição de efluentes aplicado à bacia hidrográfica do rio Piracicaba (MG). Inicialmente, foram realizados o levantamento e a preparação da base de dados geográfica, hidrológica e administrativa. O sistema foi desenvolvido utilizando tecnologias open source, sendo estruturado em três camadas: de dados, de negócios e de apresentação. De acordo com os resultados, constatou-se que os trechos mais críticos quanto à vazão passível de outorga localizam-se na foz e na cabeceira do rio Piracicaba. A análise dos dados permitiu concluir que o sistema determina, de forma consistente, a disponibilidade hídrica outorgável ao longo da hidrografia e as vazões de diluição e indisponível pelos lançamentos, além de identificar trechos dos cursos dágua com disponibilidade hídrica crítica, fornecendo subsídios para análises das outorgas quali-quantitativas dos recursos hídricos na bacia. Palavras-chave: gestão de recursos hídricos; disponibilidade hídrica; vazões mínimas.

\begin{abstract}
The granting of water use rights is one of the main management instruments for the quantitative and qualitative control of water resources. For its implementation, it is necessary, among other actions, to develop tools for integrated analysis of the quantitative and qualitative aspects of water. Thus, the objective of the study was to create a system for the analysis of water abstraction and effluent dilution in the Piracicaba river basin in Minas Gerais. Initially, the survey and preparation of the geographic, hydrological and administrative database were carried out. The system was developed using open-source technologies, with a three-layer structure: data, business, and presentation. According to the results, it was verified that the most critical sections regarding the grantable flow available are located at the mouth and spring of the Piracicaba river. The analysis of the data allowed us to conclude that the system consistently determines the availability of water throughout the hydrography, the dilution flow and discharge unavailability, and identifies stretches of the watercourses with critical water availability, providing support for analyses of the quali-quantitative granting of water resources in the basin.
\end{abstract}

Keywords: water resources management; water availability; minimum flows.

\section{INTRODUÇÃO}

A outorga de uso de água para o lançamento de esgotos e demais resíduos líquidos ou gasosos - tratados ou não —, com o fim de sua diluição, transporte ou disposição final, prevista na Lei no 9.433/1997 (BRASIL, 1997), é importante instrumento de gestão por constituir uma das formas de se evitar a escassez em termos qualitativos e os possíveis conflitos pelo uso da água, garantindo o efetivo direito de acesso dos usuários aos recursos hídricos (Wessling, 2011).

Segundo Pinheiro et al. (2013), os estados brasileiros não têm, em sua maioria, a outorga de lançamento de efluentes implantada. Enquanto

\footnotetext{
'Companhia de Pesquisa de Recursos Minerais - Manaus (AM), Brasil.

¿Universidade Federal de Viçosa - Viçosa (MG), Brasil.

${ }^{3}$ Universidade Federal do Oeste da Bahia - Barreiras (BA), Brasil.

${ }^{4}$ Universidade Federal do Mato Grosso - Sinop (MT), Brasil.

*Autor correspondente: luana.lisboa@cprm.gov.br

Recebido: 10/08/2017 - Aceito: 04/07/2018 - Reg. ABES: 183919
} 
alguns estados já possuem regulamentação específica, mas ainda não a praticam, outros estão realizando estudos para a definição dos critérios de análise.

No estado de Minas Gerais, onde o órgão gestor de recursos hídricos é o Instituto Mineiro de Gestão das Águas (IGAM), tem-se como legislações afetas à outorga para diluição de efluentes a Deliberação Normativa do Conselho Estadual de Recursos Hídricos (CERH) no 26, de 18 de dezembro de 2008 (CERH, 2008), e a Resolução Conjunta SEMAD-IGAM nº 1.548, de 29 de março de 2012.

De acordo com essa resolução, a disponibilidade hídrica máxima outorgável para as captações de água, ou seja, para os usos consuntivos, é de $50 \%$ da $\mathrm{Q}_{7,10}$ na maior parte dos cursos d'água, sendo os 50\% remanescentes destinados à diluição dos efluentes. Desse modo, o uso da água por uma modalidade de outorga não interfere na diminuição da disponibilidade hídrica de outro uso, pois as utilizações de captação de água e diluição de efluentes não são concorrentes.

O processo de implantação da outorga de diluição de efluentes no estado de Minas Gerais iniciou-se em 2008. Primeiramente, escolheu-se uma bacia-piloto crítica, a sub-bacia do Ribeirão da Mata, inserida na bacia do rio das Velhas, para validar a operacionalidade e os critérios de análise, antes de se implantar esse instrumento em todo o estado (IGAM, 2013).

Pessoa et al. (2012) afirmam que, na maioria dos órgãos gestores, as análises dos pedidos de outorga ainda são feitas através de procedimentos manuais, com a utilização de mapas, planilhas eletrônicas e outros dados de forma isolada e não integrada, tornando os processos demorados e mais suscetíveis a erros. Paralelamente, o processo de análise dos pedidos de outorga trata-se de procedimento repetitivo, com alto potencial de sistematização, o que permite a aplicação de métodos automáticos em ambientes computacionais (COLLISCHONN; LOPES, 2009).

Um sistema para gestão de recursos hídricos, além de disponibilizar informações necessárias à tomada de decisão e analisar os impactos das interferências humanas, precisa ser dinâmico e integrar os procedimentos técnicos, legais e administrativos, manter atualizado o cenário de utilização dos recursos hídricos e servir como instrumento para gestão da informação, por meio de consultas, análises e controle dos processos (MARQUES, 2010).

Dessa forma, a fim de possibilitar avanços no entendimento do comportamento da bacia e fornecer subsídios para a gestão integrada dos aspectos quantitativos e qualitativos dos recursos hídricos, o presente trabalho teve como objetivo desenvolver um sistema para análise das outorgas de captação de água e diluição de efluentes, associando os aspectos qualiquantitativos dos recursos hídricos, tendo como área de estudo a bacia hidrográfica do rio Piracicaba (MG).

\section{METODOLOGIA}

\section{Área de estudo}

A bacia hidrográfica do rio Piracicaba localiza-se no estado de Minas Gerais, na região centro-leste, com área de drenagem de $5.706 \mathrm{~km}^{2}$, e pertence à bacia do rio Doce (Figura 1). Abrangendo 20 municípios mineiros (IGAM, 2011), a população estimada na região, segundo o IBGE (2014), é de 984.236 habitantes.

Essa bacia foi uma das pioneiras a definir seu enquadramento dos cursos d'água em classes, tornando-se referência no país. O enquadramento desses cursos em classes de uso foi homologado pela Deliberação Normativa do Conselho Estadual de Política Ambiental n 9, de 19 de abril de 1994 (COPAM, 1994), passando, em 2008, por uma revisão e atualização de seus usos (atuais e futuros).

Nessa região, localiza-se um dos maiores polos da economia mineira, baseado em três atividades interligadas: mineração, reflorestamento com eucaliptos e siderurgia, as quais possuem um alto grau de impacto ambiental, sendo os recursos hídricos elementos-chave no processo de crescimento econômico e desenvolvimento sustentável da bacia (CBH PIRACICABA, 2011).

\section{Modelo digital de elevação}

Para a construção da base geográfica do sistema, foi gerado um modelo digital de elevação (MDE) da bacia. Os dados altimétricos foram obtidos do projeto Advanced Spaceborne Thermal Emission and Reflection Radiometer (ASTER), com resolução espacial de 30 metros, enquanto a hidrografia ottocodificada foi obtida na Agência Nacional de Águas (ANA), nas escalas de 1:50.000 e 1:100.000.

$\mathrm{Na}$ geração do MDE, foram utilizados os recursos do programa computacional Esri ArcGis 10.2, bem como a extensão ArcHydro, do ArcGis, visando à obtenção de um modelo hidrologicamente consistente da bacia em estudo.

Com o objetivo de validar o MDE gerado, realizou-se a comparação, por meio de sobreposição, da hidrografia numérica do MDE gerado com a ottocodificada. A metodologia de desenvolvimento e a validação do MDE encontram-se detalhadas em Maidment (2002) e Buarque et al. (2009).

\section{Disponibilidade hídrica anual}

Visando estimar a vazão mínima de referência com 7 dias de duração e o período de retorno de 10 anos $\left(\mathrm{Q}_{7,10}\right)$, adotada para fins de outorga no estado de Minas Gerais, foram analisados os dados consistidos de quatro estações fluviométricas (Tabela 1), pertencentes à rede hidrometeorológica da ANA, disponibilizados no Sistema de Informações Hidrológicas (HidroWeb).

Foram elaboradas, para cada estação fluviométrica, as séries anuais de vazões com sete dias de duração $\left(Q_{7}\right)$. Para a determinação da $Q_{7,10}$, foi identificado, para cada estação fluviométrica, o modelo probabilístico com melhor ajuste às séries de $Q_{7}$. 
Com o objetivo de otimizar as informações hidrológicas e, assim, obter a $Q_{7,10}$ em diversas seções de interesse ao longo da hidrografia, foi utilizada a técnica de regionalização de vazões descrita por Eletrobras (1985).

A determinação da vazão de referência $\left(Q_{7,10}\right)$ foi realizada utilizando-se o software SisCAH.1.0 - Sistema Computacional para Análises Hidrológicas, enquanto, para a obtenção das equações de regionalização, utilizou-se o software SisCORV.1.0 — Sistema Computacional para Regionalização de Vazões.

\section{Cadastro de usuários de água}

Considerando que o sistema proposto tem como base de dados as outorgas de captação concedidas, foi solicitado ao Instituto Mineiro de Gestão das Águas (IGAM) o cadastro de usuários de captação de água na área de abrangência da bacia hidrográfica do rio Piracicaba.

O cadastro de usuários de água utilizado para análise dos lançamentos de efluentes foi a Declaração de Carga Poluidora dos empreendimentos licenciados, disponibilizada pela Fundação Estadual do Meio Ambiente (FEAM), uma vez que o órgão gestor de recursos hídricos convocará para regularização da outorga de diluição de efluentes, inicialmente, esses empreendimentos.

\section{Vazões de diluição decorrentes dos lançamentos de efluentes}

Para cada lançamento de efluente, são necessários o cálculo da vazão apropriada para diluição da carga poluente e também a contribuição dos lançamentos a montante, e a soma desses valores não poderá ultrapassar o limite estipulado pela legislação.

Para fins de determinação da vazão de diluição, utilizou-se a metodologia proposta por Brasil (2000) e adotada pelo IGAM, em que a vazão de diluição (Equação 1) pode ser determinada por meio da equação do balanço de massa (Equação 2).

$Q_{\text {dilui }}=Q_{e} \frac{\left(C_{e}-C_{\text {máx }}\right)}{\left(C_{\text {máx }}-C_{\text {nat }}\right)}$

$C_{e} Q_{e}+C_{r} Q_{r}=C_{m}\left(Q_{e}+Q_{r}\right)$

Em que:

$\mathrm{Q}_{\text {dilui }}=$ vazão de diluição requerida do lançamento para demanda bioquímica de oxigênio (DBO) $\left(\mathrm{m}^{3} \cdot \mathrm{s}^{-1}\right)$;

$\mathrm{Q}_{\mathrm{e}}=$ vazão de lançamento do efluente $\left(\mathrm{m}^{3} \cdot \mathrm{s}^{-1}\right)$;

Tabela 1 - Estações fluviométricas utilizadas na estimativa e regionalização das vazões mínimas da Bacia do Rio Piracicaba (MG).

\begin{tabular}{l|c|c|c} 
Código & Estação & $\begin{array}{c}\text { Area de } \\
\text { drenagem }\left(\mathrm{km}^{2}\right)\end{array}$ & $\begin{array}{c}\text { Curso d'água } \\
\text { Ribeirão Santa } \\
\text { Bárbara }\end{array}$ \\
\hline 566640000 & Carrapato (Brumal) & 609 & Rio Piracicaba \\
\hline 56659998 & Rova Era IV & 3.060 & Rio Piracicaba \\
\hline 56696000 & $\begin{array}{c}\text { Mario de Carvalho } \\
\text { (PCD) }\end{array}$ & 5.270 & Rio Piracicaba \\
\hline
\end{tabular}

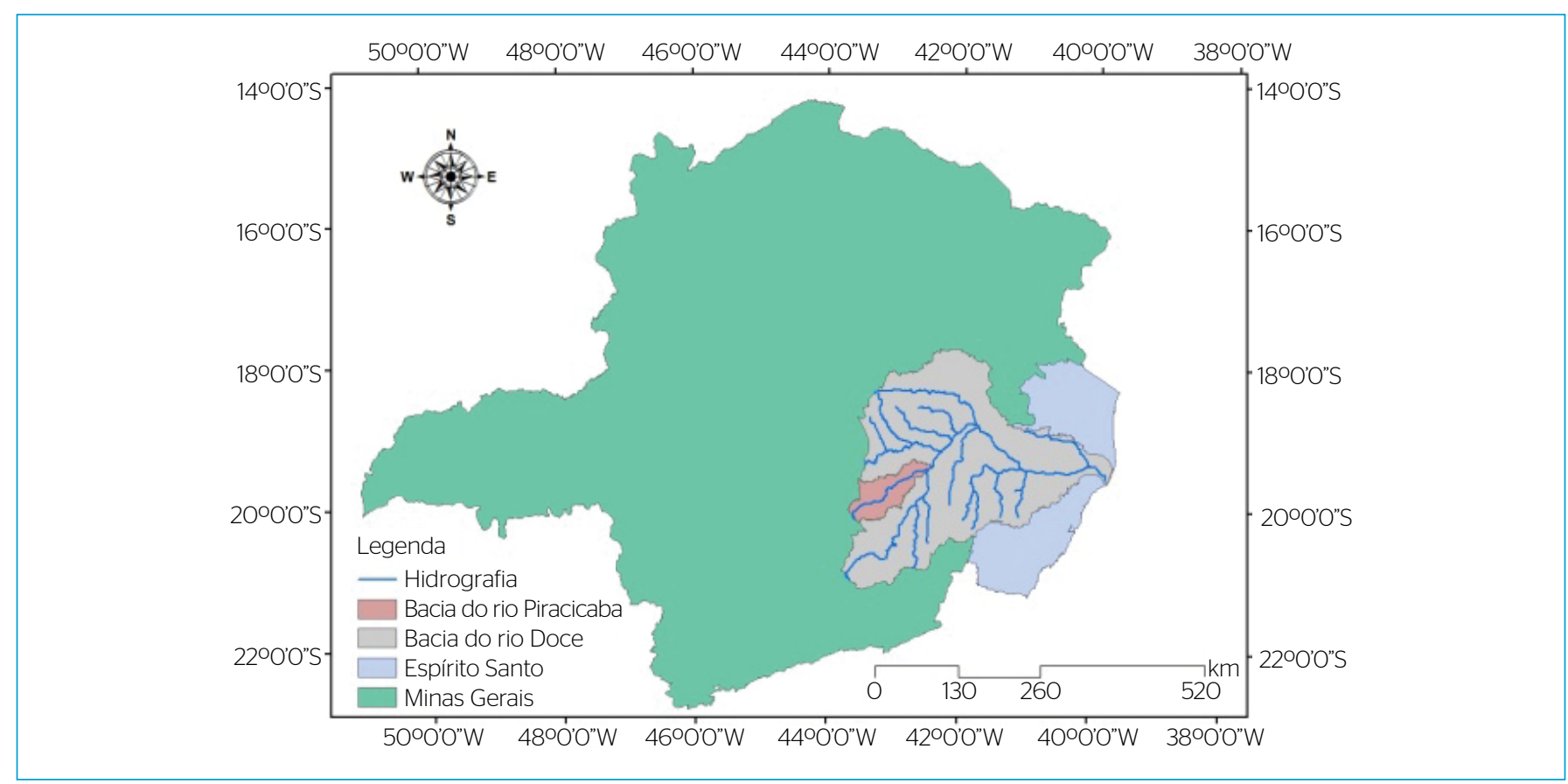

Figura 1 - Localização da bacia hidrográfica do rio Piracicaba (MG). 
$\mathrm{C}_{\mathrm{e}}=$ concentração de DBO no efluente $\left(\mathrm{mg} \cdot \mathrm{L}^{-1}\right)$;

$\mathrm{C}_{\text {máx }}=$ concentração máxima permitida de $\mathrm{DBO}$ no corpo receptor $\left(\mathrm{mg} \cdot \mathrm{L}^{-1}\right)$;

$\mathrm{C}_{\text {nat }}=$ concentração natural da DBO no rio onde é realizado o lançamento (mg. $\left.\mathrm{L}^{-1}\right)$;

$\mathrm{C}_{\mathrm{r}}=$ concentração da DBO no rio $\left(\mathrm{mg} \cdot \mathrm{L}^{-1}\right)$;

$\mathrm{Q}_{\mathrm{r}}=$ vazão do corpo receptor $\left(\mathrm{m}^{3} \cdot \mathrm{s}^{-1}\right)$;

$\mathrm{C}_{\mathrm{m}}=$ concentração da DBO no rio após a mistura com o efluente $\left(\mathrm{mg} \cdot \mathrm{L}^{-1}\right)$.

O método empregado considera ainda que a vazão indisponibilizada para outras diluições do mesmo poluente, denominada vazão de diluição, está sujeita a decaimento, caso o poluente seja de natureza não conservativa. Neste estudo, o decaimento da DBO foi baseado no modelo proposto por Streeter e Phelps (1925), citado por Von Sperling (2007).

Assim, a vazão indisponível para o parâmetro DBO, a jusante do lançamento, considerando o seu decaimento com o tempo, está representada pela Equação 3 (MARQUES, 2010; BRASIL, 2000; SALIM; ROQUES; SOUZA, 2007).

$Q_{\text {indisp }_{x}}=\frac{\left(Q_{\text {dilui }_{x 0}}+Q_{e}\right) C_{\text {máx }_{x 0}} e^{-k_{1} t}}{C_{\text {máx }}}$

Em que:

$Q_{\text {indisp }_{x}}=$ vazão que se torna indisponível em uma seção a jusante do lançamento para diluição de DBO $\left(\mathrm{m}^{3} \mathrm{~s}^{-1}\right)$;

$\mathrm{Q} e=$ vazão de lançamento do efluente $\left(\mathrm{m}^{3} \cdot \mathrm{s}^{-1}\right)$;

$Q_{\text {dilui }}=$ vazão de diluição no trecho onde ocorre o lançamento $\left(\mathrm{m}^{3} \cdot \mathrm{s}^{-1}\right)$;

$C_{\text {máx }_{x 0}}=$ concentração máxima permitida de $\mathrm{DBO}$ para o trecho do corpo receptor onde ocorre o lançamento $\left(\mathrm{mg} . \mathrm{L}^{-1}\right)$;

$C_{\text {máx }}=$ concentração máxima permitida de DBO para uma seção a jusante do lançamento onde se quer calcular a vazão indisponível $\left(\mathrm{m}^{3} \cdot \mathrm{s}^{-1}\right)$; $k_{1}=$ coeficiente de desoxigenação $\left(\operatorname{dia}^{-1}\right)$;

$t=$ tempo de percurso do ponto de lançamento até o trecho a jusante (dias).

A classe de enquadramento dos trechos dos cursos d'água foi definida utilizando os valores de concentração máxima de DBO estipulados na Resolução CONAMA nº 357/2005 (BRASIL, 2005) (classe $1=3$ mg.L $L^{-1}$ e classe $2=5 \mathrm{mg} \cdot \mathrm{L}^{-1}$ ) e definidos pela Deliberação Normativa do Conselho Estadual de Política Ambiental no 9, de 19 de abril de 1994 (CBH - PIRACICABA, 2011).

Outras variáveis necessárias ao cálculo da vazão de diluição são a concentração natural do poluente no rio e o coeficiente de desoxigenação $\left(\mathrm{K}_{1}\right)$. Este último depende das características da matéria orgânica, além da temperatura e da presença de substâncias inibidoras. Ambas as variáveis foram obtidas conforme apresentado por Von Sperling (2005).

Para a determinação do tempo de percurso do poluente entre o ponto de lançamento e a seção de interesse a jusante, considerou-se a velocidade de escoamento de 0,5 m.s. ${ }^{-1}$ (ANA, 2013; MARQUES, 2010;
COLLISCHONN; LOPES, 2009), juntamente com a distância entre as seções, determinada por meio do MDE.

\section{Vazões passíveis de outorga}

A estimativa das vazões ainda passíveis de outorga em uma seção de interesse se baseou na análise entre a disponibilidade hídrica na seção e as demandas existentes a montante e a jusante. Destaca-se que os limites máximos outorgados para captação e diluição são distintos, ou seja, $50 \%$ da $Q_{7,10}$ em uma seção do curso d'água, são destinados unicamente à captação, e o restante, isto é, a vazão remanescente correspondente aos outros $50 \% \mathrm{da}_{7,10}$, é destinado à diluição dos efluentes. A vazão disponível para novas outorgas de captações e a diluição de efluentes, considerando a análise de montante, estão representadas pelas Equações 4 e 5, respectivamente:

$Q_{\text {disp_cap }}=x Q_{m r}-\sum Q_{\text {cap }}$

$Q_{\text {disp_dilui }}=x Q_{m r}-\sum Q_{\text {indisp }}$

Em que:

$\mathrm{Q}_{\text {disp_cap }}=$ vazão disponível para novas outorgas de captação na seção de interesse, considerando as outorgas a montante $\left(\mathrm{m}^{3} \cdot \mathrm{s}^{-1}\right)$;

$\mathrm{Q}_{\text {disp_dilui }}=$ vazão disponível para novas outorgas de diluição de efluentes na seção de interesse, considerando as outorgas a montante $\left(\mathrm{m}^{3} \cdot \mathrm{s}^{-1}\right)$; $\mathrm{X}=$ percentual da $\mathrm{Q}_{\mathrm{mr}}$ passível de ser outorgada, expressa em decimal, adimensional $(0,5)$;

$\mathrm{Q}_{\mathrm{mr}}=$ vazão mínima de referência estimada na seção de interesse $\left(\mathrm{m}^{3} \cdot \mathrm{s}^{-1}\right)$; $\mathrm{Q}_{\text {cap }}=$ vazão outorgada para captação a montante da seção de interesse $\left(\mathrm{m}^{3} \cdot \mathrm{s}^{-1}\right)$;

$\mathrm{Q}_{\text {indisp }}=$ vazão indisponível referente aos lançamentos de efluentes a montante da seção de interesse $\left(\mathrm{m}^{3} \cdot \mathrm{s}^{-1}\right)$.

Na soma das vazões de captação outorgadas a montante da seção em análise, foram desenvolvidas rotinas para que o sistema consulte as interferências a montante, tendo como referência a hidrografia ottocodificada para localização.

$\mathrm{Na}$ análise da disponibilidade hídrica a jusante, o sistema identifica, para cada ponto de outorga a jusante da seção de interesse, a vazão disponível para outorga de captação, de acordo com a Equação 6:

$Q_{\text {disp_jcap }}=x Q_{m r}-\sum Q_{c a p}$

Em que:

$\mathrm{Q}_{\text {disp_cap }}=$ vazão disponível para novas outorgas a jusante da seção em análise de cada captação de água $\left(\mathrm{m}^{3} \cdot \mathrm{s}^{-1}\right)$;

$\mathrm{Q}_{\mathrm{mr}}=$ vazão mínima de referência estimada na seção de interesse $\left(\mathrm{m}^{3} \cdot \mathrm{s}^{-1}\right)$; $\mathrm{Q}_{\text {cap }}=$ vazão outorgada para captação a montante da seção de interesse $\left(\mathrm{m}^{3} \cdot \mathrm{s}^{-1}\right)$. 
Posteriormente aos cálculos feitos de disponibilidade hídrica máxima outorgável para captação de água na seção de interesse e nas seções a jusante desta, o sistema apresenta a menor vazão disponível, embasando a decisão de emitir ou não a outorga. Assim, é possível assegurar vazões remanescentes ao processo de outorga em conformidade com a legislação nos domínios de gestão (análise de jusante).

\section{RESULTADOS E DISCUSSÃO}

\section{Cadastro de outorgas de captação de água e declaração de carga poluidora}

Os usuários de captação outorgados na bacia totalizaram 57 interferências com demanda de $4,69 \mathrm{~m}^{3} \cdot \mathrm{s}^{-1}-98 \%$ desse valor correspondente a apenas três empreendimentos, localizados nas cidades de Ipatinga (MG) e Santa Bárbara (MG).

Entre as finalidades de uso observadas no cadastro de usuários outorgados para captação, citam-se: abastecimento público (17 usuários com vazão demandada de $1,026 \mathrm{~m}^{3} \cdot \mathrm{s}^{-1}$ ), consumo industrial (26 usuários com vazão demandada de $3,52 \mathrm{~m}^{3} \cdot \mathrm{s}^{-1}$ ), irrigação (6 usuários com vazão demandada de $\left.0,10 \mathrm{~m}^{3} \cdot \mathrm{s}^{-1}\right)$, extração mineral e dessedentação animal ( 8 usuários com vazão demandada de $0,04 \mathrm{~m}^{3} \cdot \mathrm{s}^{-1}$ ), entre outras finalidades. Dessa maneira, 75,05\% da vazão outorgada está representada pelo setor industrial, correspondendo a mais de $45 \%$ dos usuários outorgados.

O cadastro de empreendimentos que engloba os relatórios de Declaração de Carga Poluidora da FEAM na bacia do rio Piracicaba (MG) contempla, ao todo, 79 declarações, representadas por 19 empresas, porém nem todos os empreendimentos fazem o lançamento dos efluentes diretamente nos cursos d'água; em alguns casos, o efluente tratado é lançado no solo ou sumidouro ou recolhido por empresa especializada; direcionado através de uma instalação de recalque para outra empresa que o utiliza em seu processo; ou recirculado dentro da própria empresa, por meio da implantação do programa de descarte zero de efluentes industriais.

Assim, dos 79 empreendimentos do cadastro da FEAM, 27 foram utilizados para o cálculo da vazão de diluição e análise dos futuros pleitos de outorga, representando uma vazão total lançada de $4,44 \mathrm{~m}^{3}$.s${ }^{-1}$ ou $3.836 .460,16 \mathrm{~m}^{3} \cdot \mathrm{mês}^{-1}$.

\section{Apresentação do sistema}

A Figura 2 exibe a tela de apresentação do sistema para análise das outorgas de captação de água e diluição de efluentes na bacia do rio Piracicaba (MG), constando seu nome, as instituições envolvidas e a barra de ferramentas superior, assim como o menu principal (funcionalidades). Para melhor visualização dos mapas exibidos nessa tela, o usuário pode clicar sobre cada um deles e, assim, aumentar o seu tamanho.

$\mathrm{Na}$ barra de ferramentas em destaque na Figura 2, no campo referente às "Análises", é possível acessar as funcionalidades do sistema, a citar: consultas das vazões mínimas de referência para qualquer seção de interesse ao longo da hidrografia, as vazões de diluição e indisponíveis pelos lançamentos e a disponibilidade hídrica na bacia.

No campo "Cadastros", é possível incluir um novo usuário ao banco de dados, assim como novos requerentes, analistas, processos de outorga, intervenções, entre outros. Também é possível editar as informações já cadastradas, ou seja, fazer modificações no banco de dados do sistema.

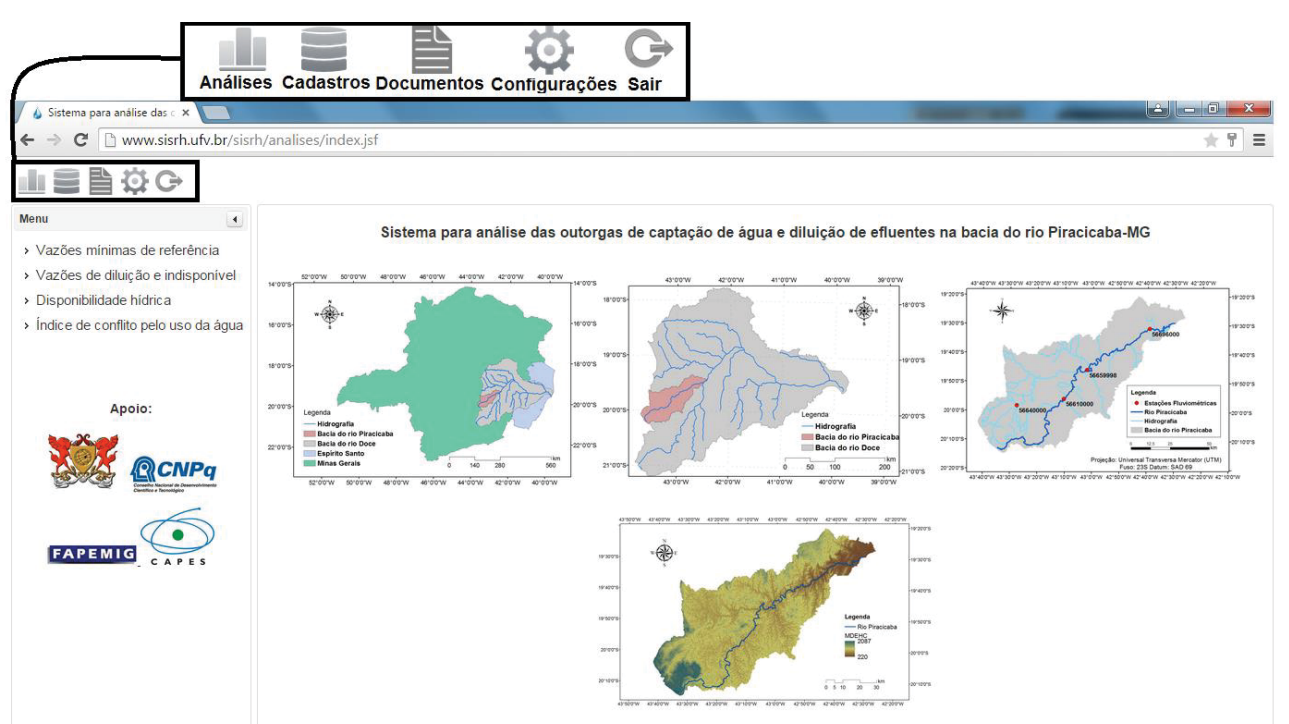

Figura 2 - Tela de apresentação do sistema para análise das outorgas de captação de água e diluição de efluentes na bacia do rio Piracicaba (MG). 
No campo "Documentos", estão disponíveis arquivos de interesse para a bacia do rio Piracicaba (MG), como seu enquadramento, o plano de ações de recursos hídricos, legislações pertinentes em níveis federal e estadual, entre outros.

O campo “Configurações” é utilizado pelo administrador do sistema para programação das rotinas, enquanto o "Sair" permite ao usuário se desconectar do sistema.

\section{Disponibilidade hídrica passível de outorga ao longo do rio Piracicaba (MG)}

Para a análise da disponibilidade hídrica passível de outorga, fez-se um estudo de caso selecionando pontos de interesse ao longo do rio Piracicaba (MG), com as seguintes áreas de drenagem: seções $1\left(5.465,0 \mathrm{~km}^{2}\right), 2\left(3.031,0 \mathrm{~km}^{2}\right)$ e $3\left(50,0 \mathrm{~km}^{2}\right)$.

A primeira seção utilizada para análise localiza-se próxima à foz do rio, a jusante de todas as intervenções referentes à captação de água e diluição de efluentes, com área de drenagem de $5.465,69 \mathrm{~km}^{2}$. Na Figura 3, é apresentado o relatório com resultados exibidos pelo sistema para a disponibilidade hídrica passível de outorga em uma seção de interesse no rio Piracicaba (MG), com área de drenagem igual a 5.465,69 km².

Os resultados de disponibilidade hídrica para as captações de água variaram mês a mês, ao longo do período analisado. Tal fato se justifica em função da sazonalidade de algumas outorgas presentes no cadastro de usuários do IGAM, que possuem demandas diferentes durante o período solicitado, bem como em função das diferentes validades dos processos de outorgas.

No caso da disponibilidade hídrica para diluição de efluentes, no entanto essa variação não ocorre, uma vez que esse comportamento se deve à não sazonalidade dos lançamentos de efluentes, pois a vazão de lançamento é a mesma durante todos os meses do ano, e os usuários possuem a validade da outorga, com início em 2011 e término em 2015.

Verifica-se que o menor valor de vazão disponível para novas outorgas de captação ocorreu nos meses de fevereiro e março de 2013, sendo igual a $10,38 \mathrm{~m}^{3} \cdot \mathrm{s}^{-1}$, ou seja, houve redução de $23 \%$ do limite máximo, equivalente à demanda dos usuários de $3,06 \mathrm{~m}^{3} \cdot \mathrm{s}^{-1}$. Porém, a partir de junho de 2014, esse valor aumentou para $11,44 \mathrm{~m}^{3} \cdot \mathrm{s}^{-1} \mathrm{e}$, emjaneiro de 2015, a disponibilidade hídrica foi de $11,79 \mathrm{~m}^{3} \cdot \mathrm{s}^{-1}(82,3 \%)$.

A vazão disponível para novas outorgas de diluição de efluentes, considerando o período analisado (Figura 3 ), foi de $7,25 \mathrm{~m}^{3} \cdot \mathrm{s}^{-1}$, ou seja, houve diminuição de $6,18 \mathrm{~m}^{3} \cdot \mathrm{s}^{-1}$, que é a vazão indisponibilizada pelos lançamentos a montante da foz do rio Piracicaba. Esse valor representa $46 \%$ do total disponível para diluição dos efluentes, constatando-se, assim, comprometimento considerável dessa modalidade de outorga, pois esse valor é bem maior que o do comprometimento destinado às captações de água nessa seção.

\begin{tabular}{|l|c|}
\hline \multicolumn{2}{|c|}{ Caracteristicas hidrológicas da seção de interesse } \\
\hline Curso d’água: & Rio Piracicaba \\
\hline Area de drenagem $\left(\mathrm{km}^{2}\right):$ & 5465.687400 \\
\hline Classe do rio & 2 \\
\hline Vazão mínima de referência $\left(\mathrm{m}^{3} \cdot \mathrm{s}^{-1}\right):$ \\
\hline $\mathrm{Q}_{7,0}$ anual: & 26.887162 \\
\hline Vazão máxima outorgável $\left(\mathrm{m}^{3} \cdot \mathrm{s}^{-1}\right):$ \\
\hline $50 \%$ Q \\
\hline
\end{tabular}

\begin{tabular}{|c|c|c|c|c|c|c|c|c|c|c|c|c|}
\hline \multicolumn{13}{|c|}{ Vazões disponiveis para captação $\left(\mathrm{m}^{3} . \mathrm{s}^{-1}\right)$} \\
\hline Ano & Jan. & Fev. & Mar. & Abr. & Maio & Jun. & Jul. & Ago. & Set. & Out. & Nov. & Dez. \\
\hline 2012 & 11.097481 & 10.987481 & 10.435081 & 10.432081 & 10.428881 & 10.512081 & 10.550081 & 10.542381 & 10.540781 & 10.540781 & 10.538881 & 10.538881 \\
\hline 2013 & 10.483881 & 10.383681 & 10.383181 & 10.509581 & 10.544181 & 10.624181 & 10.689181 & 10.689181 & 10.689181 & 10.911181 & 10.909281 & 10.909281 \\
\hline 2014 & 10.851281 & 10.745481 & 10.744981 & 10.758181 & 10.761381 & 11.440381 & 11.523381 & 11.551181 & 11.551181 & 11.551181 & 11.549281 & 11.549281 \\
\hline 2015 & 11.787281 & 11.679481 & 11.748381 & 11.747581 & 11.750781 & 11.860781 & 11.936781 & 11.936781 & 11.936781 & 11.956781 & 11.954881 & 11.954881 \\
\hline \multicolumn{13}{|c|}{ Vazões disponiveis para lançamento $\left(\mathrm{m}^{3} . \mathrm{s}^{-1}\right)$} \\
\hline Ano & Jan. & Fev. & Mar. & Abr. & Maio & Jun. & Jul. & Ago. & Set. & Out. & Nov. & Dez. \\
\hline 2012 & 7.257117 & 7.257117 & 7.257117 & 7.257117 & 7.257117 & 7.257117 & 7.257117 & 7.257117 & 7.257117 & 7.257117 & 7.257117 & 7.257117 \\
\hline 2013 & 7.257117 & 7.257117 & 7.257117 & 7.257117 & 7.257117 & 7.257117 & 7.257117 & 7.257117 & 7.257117 & 7.257117 & 7.257117 & 7.257117 \\
\hline 2014 & 7.257117 & 7.257117 & 7.257117 & 7.257117 & 7.257117 & 7.257117 & 7.257117 & 7.257117 & 7.257117 & 7.257117 & 7.257117 & 7.257117 \\
\hline 2015 & 7.257117 & 7.257117 & 7.257117 & 7.257117 & 7.257117 & 7.257117 & 7.257117 & 7.257117 & 7.257117 & 7.257117 & 7.257117 & 7.257117 \\
\hline
\end{tabular}

Figura 3 - Relatório da disponibilidade hídrica passível de outorga em uma seção de interesse no rio Piracicaba (MG), com área de drenagem igual a $5.465,69 \mathrm{~km}^{2}$. 
Esse resultado é devido, principalmente, a um lançamento realizado, que se localiza próximo à foz do rio Piracicaba (MG) e indisponibiliza uma vazão de $5,52 \mathrm{~m}^{3} \cdot \mathrm{s}^{-1}$. Assim, a vazão indisponibilizada pelos lançamentos nessa seção é de $6,18 \mathrm{~m}^{3} \cdot \mathrm{s}^{-1} \mathrm{e}$, desse valor, $90 \%$ corresponde ao lançamento citado anteriormente, sendo os $10 \%$ restantes referentes aos demais lançamentos a montante.

A segunda seção analisada quanto à disponibilidade hídrica apresenta área de drenagem de $3.031,59 \mathrm{~km}^{2}$ e localiza-se no município de Nova Era (MG). Para essa seção, a $Q_{7,10}$ é de $15,57 \mathrm{~m}^{3} \cdot \mathrm{s}^{-1}$, e a vazão máxima passível de outorga, de $7,78 \mathrm{~m}^{3} \cdot \mathrm{s}^{-1}$ (Figura 4). No entanto, considerando as demandas dos usuários, a disponibilidade hídrica para captação de água e diluição de efluentes em janeiro de 2012 foi de 5,96 e 7,46 $\mathrm{m}^{3} . \mathrm{s}^{-1}$, respectivamente. Dessa forma, houve redução de $1,82 \mathrm{~m}^{3} \cdot \mathrm{s}^{-1}$ para captação de água e $0,33 \mathrm{~m}^{3} \cdot \mathrm{s}^{-1}$ para diluição de efluentes, ou seja, 23 e 4,2\%, respectivamente. Assim, o comprometimento com as captações de água foi maior $\left(1,49 \mathrm{~m}^{3} \cdot \mathrm{s}^{-1}\right)$, em comparação com a demanda das diluições de efluentes.

Outra seção de interesse utilizada para análise da disponibilidade hídrica ao longo do rio Piracicaba (MG) foi próxima à cabeceira, a jusante de um conjunto de lançamentos, com área de drenagem correspondente a $50,13 \mathrm{~km}^{2}$ (Figura 5). A $\mathrm{Q}_{7,10}$ está representada por $0,34 \mathrm{~m}^{3} \cdot \mathrm{s}^{-1}$, e a disponibilidade hídrica máxima outorgável para captação e diluição de efluentes é $0,17 \mathrm{~m}^{3} \cdot \mathrm{s}^{-1}$.
De acordo com resultados da simulação apresentados na Figura 5, o limite outorgável para diluição de efluentes foi superado em $0,188 \mathrm{~m}^{3} \cdot \mathrm{s}^{-1}$, constatando-se que a demanda nessa seção superou a vazão mínima de referência. Verifica-se que a montante da seção de interesse estão localizados cinco lançamentos, e a vazão indisponibilizada totaliza $0,354 \mathrm{~m}^{3} \cdot \mathrm{s}^{-1}$, valor superior ao máximo permitido pela legislação de Minas Gerais.

$A$ vazão outorgada superior ao valor da $Q_{7,10}$ não implica, necessariamente, eliminação total da vazão no curso d'água, uma vez que a $\mathrm{Q}_{7,10}$ corresponde a um índice probabilístico relacionado ao risco de ocorrência de um evento a cada 10 anos. Além disso, o valor da vazão outorgada corresponde ao somatório das outorgas, o que não implica retirada simultânea dessas vazões (MOREIRA et al., 2014).

Para as captações, a disponibilidade hídrica está dentro do limite estipulado pelo órgão gestor de recursos hídricos durante o intervalo de tempo analisado. No entanto, no período de agosto de 2012 a fevereiro de 2015,49\% da vazão total para outorgas está atendendo à demanda dos usuários. A partir do mês de março de 2015, a vazão outorgável aumenta para $0,159 \mathrm{~m}^{3} . \mathrm{s}^{-1}(77 \%)$, o que é justificado pelo vencimento das outorgas.

Pelos resultados das simulações da disponibilidade hídrica ao longo do rio Piracicaba (MG), constata-se que, em alguns trechos da hidrografia, é necessária a revisão dos processos de outorga para a captação de água, uma vez que a disponibilidade hídrica supera

\begin{tabular}{|c|c|c|c|c|c|c|c|c|c|c|c|c|}
\hline \multicolumn{13}{|c|}{ Caracteristicas hidrológicas da seção de interesse } \\
\hline \multicolumn{3}{|c|}{ Curso d’água: } & \multicolumn{2}{|c|}{ Rio Piracicaba } & & & & & & & & \\
\hline \multicolumn{3}{|c|}{ Área de drenagem $\left(\mathrm{km}^{2}\right)$ : } & \multicolumn{2}{|c|}{3031.598700} & & & & & & & & \\
\hline \multicolumn{3}{|c|}{ Classe do rio } & \multicolumn{2}{|c|}{2} & & & & & & & & \\
\hline \multicolumn{5}{|c|}{ Vazão mínima de referência $\left(m^{3} \cdot s^{-1}\right)$ : } & & & & & & & & \\
\hline $\mathrm{Q}_{7,10}$ ar & & & \multicolumn{2}{|c|}{15.579676} & & & & & & & & \\
\hline \multicolumn{5}{|c|}{ Vazão máxima outorgável $\left(\mathrm{m}^{3} \cdot \mathrm{s}^{-1}\right)$ : } & & & & & & & & \\
\hline \multicolumn{3}{|c|}{$50 \% Q_{7,10}$ anual: } & \multicolumn{2}{|c|}{7.789838} & & & & & & & & \\
\hline \multicolumn{13}{|c|}{ Vazões disponiveis para captação $\left(\mathrm{m}^{3} \cdot \mathrm{s}^{-1}\right)$} \\
\hline Ano & Jan. & Fev. & Mar. & Abr. & Maio & Jun. & Jul. & Ago. & Set. & Out. & Nov. & Dez. \\
\hline 2012 & 5.963338 & 5.963338 & 5.960938 & 5.957938 & 5.954738 & 5.954738 & 5.992738 & 5.986738 & 5.985138 & 5.985138 & 5.983238 & 5.983238 \\
\hline 2013 & 5.928238 & 5.928238 & 5.927738 & 6.051938 & 6.056538 & 6.056538 & 6.111538 & 6.111538 & 6.111538 & 6.333538 & 6.331638 & 6.331638 \\
\hline 2014 & 6.276638 & 6.276638 & 6.276138 & 6.289338 & 6.292538 & 6.861538 & 6.916538 & 6.944338 & 6.944338 & 6.944338 & 6.942438 & 6.942438 \\
\hline 2015 & 6.887438 & 6.889638 & 6.958538 & 6.957738 & 6.960938 & 6.960938 & 7.015938 & 7.015938 & 7.015938 & 7.035938 & 7.034038 & 7.034038 \\
\hline \multicolumn{13}{|c|}{ Vazões disponiveis para lançamento $\left(\mathrm{m}^{3} \cdot \mathrm{s}^{-1}\right)$} \\
\hline Ano & Jan. & Fev. & Mar. & Abr. & Maio & Jun. & Jul. & Ago. & Set. & Out. & Nov. & Dez. \\
\hline 2012 & 7.456075 & 7.456075 & 7.456075 & 7.456075 & 7.456075 & 7.456075 & 7.456075 & 7.456075 & 7.456075 & 7.456075 & 7.456075 & 7.456075 \\
\hline 2013 & 7.456075 & 7.456075 & 7.456075 & 7.456075 & 7.456075 & 7.456075 & 7.456075 & 7.456075 & 7.456075 & 7.456075 & 7.456075 & 7.456075 \\
\hline 2014 & 7.456075 & 7.456075 & 7.456075 & 7.456075 & 7.456075 & 7.456075 & 7.456075 & 7.456075 & 7.456075 & 7.456075 & 7.456075 & 7.456075 \\
\hline 2015 & 7.456075 & 7.456075 & 7.456075 & 7.456075 & 7.456075 & 7.456075 & 7.456075 & 7.456075 & 7.456075 & 7.456075 & 7.456075 & 7.456075 \\
\hline
\end{tabular}

Figura 4 - Relatório da disponibilidade hídrica passível de outorga em uma seção de interesse no rio Piracicaba (MG), com área de drenagem de 3.031,59 km². 


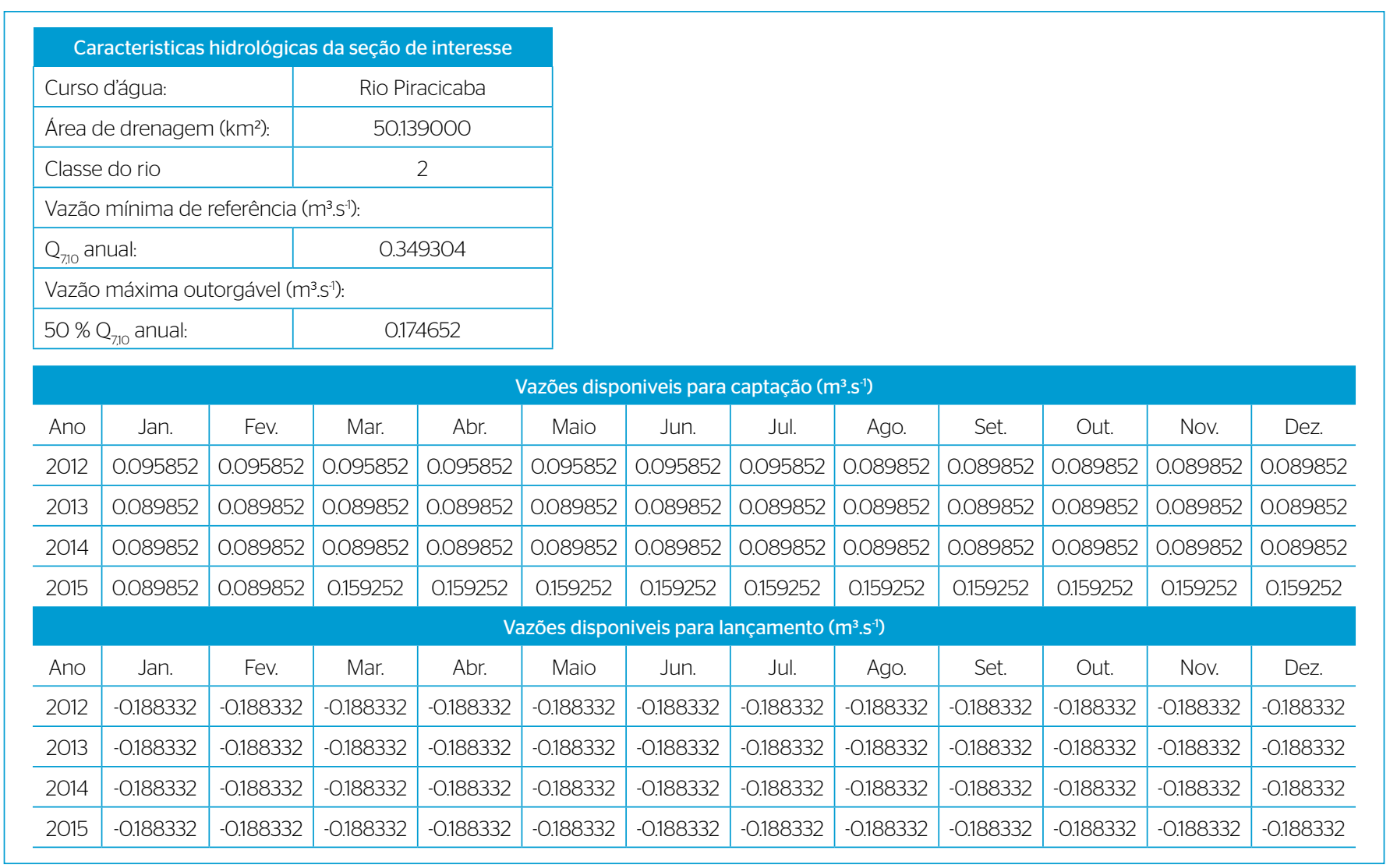

Figura 5 - Relatório da disponibilidade hídrica passível de outorga em uma seção de interesse no rio Piracicaba (MG), com área de drenagem de $50,10 \mathrm{~km}^{2}$.

o limite máximo de vazão outorgável, principalmente na foz do rio Piracicaba, e mostra-se também necessário melhor planejamento na implantação da modalidade de outorga para diluição de efluentes, pois verifica-se comprometimento do manancial acima dos limites estabelecidos pelo respectivo enquadramento, já que não há vazão para diluir todos os lançamentos.

\section{CONCLUSÕES}

A análise dos resultados permite concluir:
- o sistema para análise das outorgas de captação de água e diluição de efluentes na bacia do rio Piracicaba (MG) permite calcular, de forma consistente, as vazões mínimas de referência anuais em qualquer seção ao longo da hidrografia; a estimativa da disponibilidade hídrica mensal; as vazões de diluição e indisponível pelos lançamentos; e a identificação de trechos dos cursos d'água críticos quanto à disponibilidade hídrica;

- os trechos considerados mais críticos quanto à vazão passível de outorga para as captações de água e a diluição de efluentes se localizam próximos da foz e da cabeceira do rio Piracicaba (MG).

\section{REFERÊNCIAS}

AGÊNCIA NACIONAL DE AGUAS (ANA). (2013) Manual de procedimentos técnicos e administrativos de outorga de direito de uso de recursos hídricos da Agência Nacional de Águas. Brasília: ANA. 237 p.

BRASIL. (1997) Política Nacional de Recursos Hídricos. Lei no 9.433, de 8 de janeiro de 1997. Institui a Política Nacional de Recursos
Hídricos e cria o Sistema Nacional de Recursos Hídricos. Diário Oficial [da República Federativa do Brasil], Brasília.

BRASIL. (2000) Ministério do Meio Ambiente. Secretaria de Recursos Hídricos. Sistemas de Apoio ao Gerenciamento de Usuários da Água - SISAGUA. Brasília. 
BRASIL. (2005) Resolução no 357, de 17 de março de 2005, do Conselho Nacional do Meio Ambiente (CONAMA). Dispõe sobre a classificação dos corpos de água e diretrizes ambientais para o seu enquadramento, bem como estabelece as condições e padrões de lançamento de efluentes, e dá outras providências. Diário Oficial [da República Federativa do Brasil]. Brasília: Poder Executivo, 18 mar. 2005.

BUARQUE, D.C.; FAN, F.M.; PAZ, A.R.; COLLISCHONN, W. (2009) Comparação de Métodos para Definir Direções de Escoamento a partir de Modelos Digitais de Elevação. Revista Brasileira de Recursos Hídricos, v. 14, n. 2, p. 91-103.

CENTRAIS ELÉTRICAS BRASILEIRAS S.A. (ELETROBRAS). (1985) Metodologia para Regionalização de Vazões. Rio de Janeiro: Eletrobras.

COLLISCHONN, B.; LOPES, A.V. (2009) Sistema de apoio à decisão para análise de outorga na bacia do rio Paraná. In: SIMPÓSIO BRASILEIRO DE RECURSOS HÍDRICOS, 18., 2009, Campo Grande. Anais... Campo Grande.

COMITÊ DA BACIA HIDROGRÁFICA DO RIO PIRACICABA (CBH PIRACICABA). Portal. (2011). Disponível em: < http://www. cbhpiracicabamg.org.br>. Acesso em: 10 dez. 2011.

CONSELHO ESTADUAL DE POLITICA AMBIENTAL (COPAM). (1994) Deliberação Normativa COPAM no 09, de 19 de abril de 1994. Dispões sobre o enquadramento da Bacia do rio Piracicaba MG. Belo Horizonte.

CONSELHO ESTADUAL DE RECURSOS HÍDRICOS (CERH). (2008) Deliberação Normativa no 26, de 18 de dezembro de 2008. Dispõe sobre procedimentos gerais de natureza técnica e administrativa a serem observados no exame de pedidos de outorga para o lançamento de efluentes em corpos de água superficiais no domínio do Estado de Minas Gerais. Belo Horizonte.

INSTITUTO BRASILEIRO DE GEOGRAFIA E ESTATÍSTICA. (2014) Anuário estatístico do Brasil. Rio de Janeiro. Disponível em: <https:// biblioteca.ibge.gov.br/visualizacao/periodicos/2O/aeb 2014.pdf>. Acesso em: 20 maio 2014.

INSTITUTO MINEIRO DE GESTÃO DAS AGUAS (IGAM). Bacia Hidrográfica do Rio Doce: Bacia Hidrográfica do Rio Piracicaba. Belo Horizonte: IGAM. Disponível em: <http://www.igam.mg.gov.br/ index.php?option=com_content\&task=view\&id=155\&ltemid=140>. Acesso em: 15 nov. 2011.

INSTITUTO MINEIRO DE GESTÃO DAS ÁGUAS (IGAM). (2012) Resolução Conjunta SEMAD-IGAM no 1.548, de 29 de março 2012. Dispõe sobre a vazão de referência para o cálculo da disponibilidade hídrica superficial nas bacias hidrográficas do Estado de Minas Gerais. Belo Horizonte: IGAM.
INSTITUTO MINEIRO DE GESTÃO DAS ÁGUAS (IGAM). (2013) Outorga de lançamento de efluentes na bacia do Ribeirão da Mata. Belo Horizonte: IGAM. 137 p.

MAIDMENT, D.R. (2002). Arc Hydro: GIS for water resources. 1 ed. California: ESRI Press. Redlands.

MARQUES, F.A. (2010) Sistema de Controle Dinâmico para a Gestão dos Usos Múltiplos da Água. 234f. Tese (Doutorado em Engenharia Agrícola) - Universidade Federal de Viçosa, Viçosa.

MOREIRA, M.C.; SILVA, D.D. da; LARA, M. dos S.; PRUSKI, F.F. (2014) Índices de conflito pelo uso da água da bacia do ribeirão entre Ribeiros. Revista Brasileira de Recursos Hidricos, v. 19, n. 1, p. 221-228. http://dx.doi.org/10.21168/rbrh.v19n1.p221-228

PESSOA, M.M.E.P.; KAYSER, R.B.; COLLISCHONN, W. (2012) Integração do Modelo Hidrológico para Grandes Bacias MGB-IPH e Sistemas de Informação Geográfica para suporte a decisão de outorga de direito de uso da água. Revista de Gestão de Água da América Latina, v. 9, n. 2, p. 21-33. http://dx.doi.org/10.21168/rega. v9n2.p21-33

PINHEIRO, R.B.; MONTENEGRO, S.M.G.L.; SILVA, S.R.; MEDEIROS, Y.D.P., AURELIANO, J.T. (2O13) Outorga para lançamento de efluentes - Uma metodologia de apoio à gestão de recursos hídricos. Revista Brasileira de Recursos Hídricos, v. 18, n. 4, p. 55-65. http://dx.doi.org/10.21168/rbrh.v18n4.p55-65

SALIM, F.P.C.; ROQUES, T.V.P.; SOUZA, W.G. (2007) Definição de critérios técnicos de análise de outorga para diluição de efluentes em cursos d’água: o caso do Estado do Espírito Santo. In: SIMPÓSIO BRASILEIRO DE RECURSOS HÍDRICOS, 17., 2007, São Paulo. Anais... São Paulo: Associação Brasileira de Recursos Hídricos.

STREETER, H.W.; PHELPS, E.B. (1925) A study of the pollution and natural purification of the Ohio River. Public Health Bulletin. Washington, D.C. $146 \mathrm{p}$

VON SPERLING, M. (2005) Introdução à Qualidade das Águas e ao Tratamento de Esgotos. 3. ed. Belo Horizonte: Departamento de Engenharia Sanitária e Ambiental, Universidade Federal de Minas Gerais. v. 1. 452 p.

VON SPERLING, M. (2007) Estudos e modelagem da qualidade da água de rios. Belo Horizonte: Departamento de Engenharia Sanitária e Ambiental, Universidade Federal de Minas Gerais. p. 317-576.

WESSLING, C.S. (2011) Avaliação comparativa entre os procedimentos técnicos legais e administrativos para lançamento de efluentes em rios adotados no Brasil e Alemanha. 186f. Dissertação (Mestrado em Meio Ambiente Urbano e Industrial) Universidade Federal do Paraná, Curitiba. 